\title{
The potential of unmanned aerial vehicles for providing information on vegetation health
}

\author{
M. F. McCabe ${ }^{\text {a }}$, R. Houborg ${ }^{\text {a }}$ and J. Rosas ${ }^{\text {a }}$ \\ ${ }^{a}$ Division of Biological and Environmental Sciences and Engineering, King Abdullah University of Science \\ and Technology, Thuwal, Saudi Arabia \\ Email: matthew.mccabe@kaust.edu.sa
}

\begin{abstract}
The accurate and timely retrieval of agricultural water use, crop health and related plant biophysical parameters, represent key elements in delivering an effective crop management and monitoring strategy. In arid and semi-arid environments, where the availability of water is generally limited, determining the dynamics of these variables is especially important. With the rapid developments in unmanned aerial vehicles (UAVs), the capacity to develop customized retrievals of crop information now exists. While there remain challenges in the routine application of autonomous airborne systems, the state of current technology together with sensor developments provide an opportunity to further explore the operational potential. UAVs offer the capacity to bridge the spatio-temporal divide that exists between satellite and ground based sensing, offering new insights into process dynamics and behavior and providing the data necessary to produce a truly multi-scale framework for improved agricultural characterization. In this paper we will focus on the retrieval of vegetation parameters from UAV platforms, using high-resolution satellite data from RapidEye and Landsat sensors to evaluate retrievals. A focus on traditional parameters such as the Normalised Difference Vegetation Index (NDVI) and Leaf Area Index (LAI) will be supplemented with estimates of thermal infrared based land surface temperature. We will also discuss how UAVs can support the development of farm-level monitoring, particularly in the determining crop water-use and crop health.
\end{abstract}

Keywords: $\quad$ Unmanned Aerial Vehicles (UAV), NDVI, LAI, land surface temperature, agriculture 


\section{INTRODUCTION}

One of the challenges facing the Earth and related environmental sciences is the degradation of in-situ monitoring networks. Indeed, while national hydro-meteorological monitoring networks are in general decline globally, in agricultural applications there is actually little to no infrastructure for the assessment of variables such as crop water use, health and production. Even in advanced agricultural systems, it is only in recent times that groundwater abstraction rates have been directly monitored and only then in those countries where reporting of such information is required by enacted legislation (Nevill, 2009). For example, in California, where the state has been gripped by a prolonged and intense drought for the last $3+$ years (Mao et al., 2015), groundwater is the crutch to that states $\$ 45$ billion dollar agriculture industry (Famiglietti et al., 2011). Yet even in one of the most agriculturally advanced regions, extraction rates remains largely unregulated, and unmonitored withdrawals have driven water levels to historical lows. Obviously, there is an information vacuum restricting the development of effective and sustainable environmental management, but this particularly so in the agricultural and hydrological sciences. Developing a monitoring capacity to fill this void will facilitate improved water accounting and crop assessment in the agricultural sector as well as fulfilling numerous other application driven science objectives in related disciplines.

Given the paucity of in-situ data, satellite observations provide an attractive means to infer agricultural response across a range of space and time scales (McCabe and Wood, 2006). Many methodological advances have been made over the last few decades to provide a strong basis for retrieving terrestrial water use using satellite data (Kalma et al., 2008). Indeed, most of these techniques have been adapted from traditional approaches for estimating crop evapotranspiration (i.e. crop water use)(Ershadi et al., 2015). However, even the best available satellite retrievals are limited by both space and time constraints (Fig. 1). Indeed, crop water use can only be retrieved at a resolution of approximately $100 \mathrm{~m}$ every 17 days using Landsat 8 data (Ershadi et al., 2013), which is insufficient to resolve the level of within-field scale variability required for precision agricultural management. Despite advances in satellite sensor technologies, uptake within the agricultural sector has been limited, due to latency in satellite data processing and delivery, the prohibitive expense of commercial satellites (a single tasked overpass costs several thousand dollars) and a lack of systems for integrating data into products useable by the farmer (Zhang and Kovacs, 2012). In agriculture, for a farmer to make field level decisions regarding crop health, irrigation scheduling or fertilizer and pesticide application requires high-resolution information to inform precision agriculture applications.

Drones, or more commonly unmanned aerial vehicles (UAVs), provide the next frontier in Earth observation (Dunbabin and Marques, 2012; Hardin and Jensen, 2011; Watts et al., 2012). The rise of UAVs has received much attention in the mainstream media, with many reports highlighting the transformative nature of this technology. Previously the predominant domain of military agencies, the recent availability of affordable enthusiast level systems has driven a revolution in this field of remote sensing. Areas as diverse as 3D mapping (Nex and Remondino, 2014), search and rescue (Tomic et al., 2012), spatial ecology (Anderson and Gaston, 2013) and ecohydrology (Vivoni et al., 2014) have taken advantage of this new observation platform. Of interest here is the potential of UAVs to provide information to drive advanced applications in agriculture (Herwitz et al., 2004; Zhang and Kovacs, 2012), especially in the retrieval of vegetation information (Houborg et al., 2015a; Liu et al., 2011), surface temperature (McCabe et al., 2008) and also in estimating crop water use via evaporation (Ershadi et al., 2014; Kalma et al., 2008).

Here we present some preliminary results from a UAV based monitoring system that aims to provide crop level information on plant health, function and condition and that can drive further advances in the development of techniques for estimating crop water use.

\section{UNMANNED AERIAL VEHICLE (UAV) SYSTEMS AT KAUST}

In order to develop a UAV capacity at KAUST, two systems have been deployed for remote sensing applications (Figure 1). A fixed wing (QuestUAV; http://www.questuav.com/) and a custom built quadcopter solution (FalconVIZ; http://www.falconviz.com/) provide UAV capacity with replicate sensor packages (see Figure 1). These different platforms offer complimentary features such as variable spatial resolution, vertical profiling, hovering and speed control. The quad-copter is a multi-rotor capable of carrying large payloads. The primary sensor package includes a Tetracam multispectral camera (MiniMCA) as well as an Optris thermal camera. The lightweight carbon fiber frame and high efficiency motors allows for flight times from 40 minutes (payload less than $500 \mathrm{~g}$ ) to 25 minutes (payload of $3000 \mathrm{~g}$ ). These flight times allow for larger areas to be covered than generally available from a conventional multirotor. The $1.3 \mathrm{~m}$ diameter frame is also foldable allowing for ease of transport. The QuestUAV offers similar flight durations, but has an advantage of faster air-speeds (up to $20 \mathrm{~m} / \mathrm{s}$ versus around $10 \mathrm{~m} / \mathrm{s}$ for the quad-copter), providing for greater spatial coverage. 

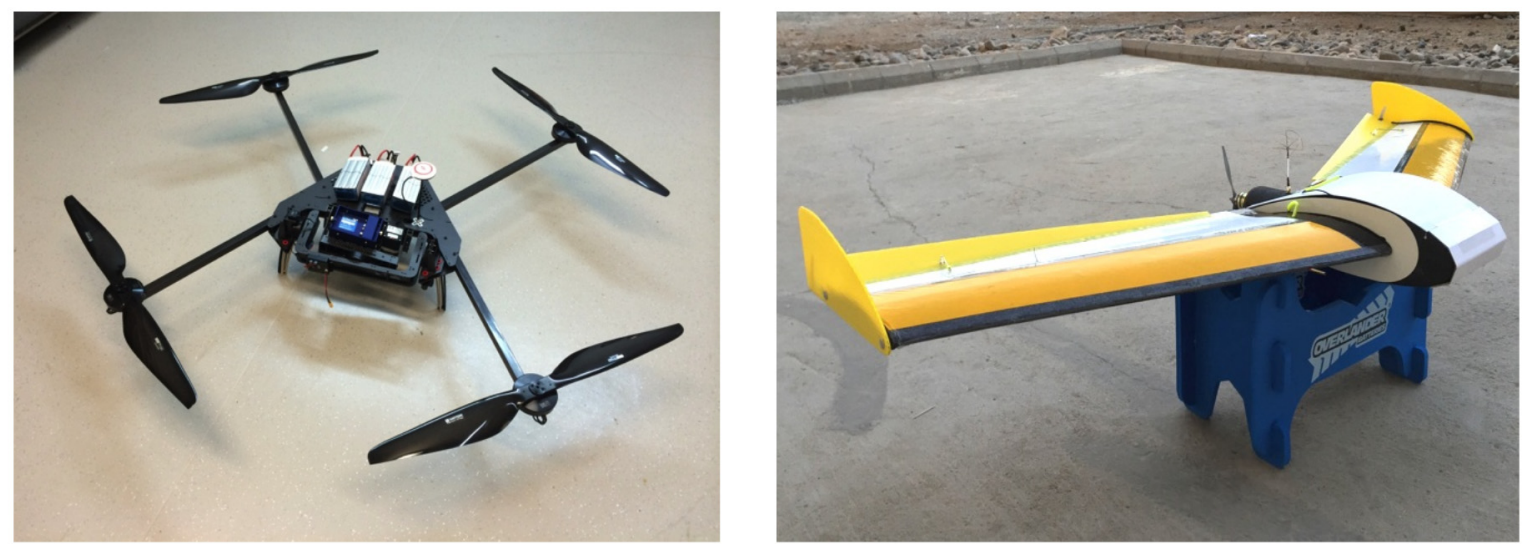

Figure 1. (left) a custom-designed quadcopter with a sensor load of just over $1 \mathrm{~kg}$; and (right) the QuestUAV system. The UAVs carry a common sensor package comprising a SONY NEX-7 20MP digital camera, an Optris-Pi450 broadband thermal camera $(7.5$ to $13 \mu \mathrm{m})$ and a Tetracam MiniMCA that records 6 unique spectral bands across the VNIR (i.e. 490, 560, 665, 705, 740, $865 \mathrm{~nm}$ center wavelengths) that is configured to match those on Sentinel-2, a new satellite system launched in June 2015.

\section{VEGETATION PRODUCT RETRIEVAL FROM SATELLITE AND UAV DATA}

Preliminary vegetation retrievals using the commonly applied Normalised Difference Vegetation Index (NDVI) and Leaf Area Index (LAI) (Carlson and Ripley, 1997) were derived from the Tetracam MiniMCA system and also from available and near-coincident satellite imagery via the Landsat and RapidEye systems. Multi-spectral (blue, green, red, red-edge, near-infrared) at-sensor radiance data from RapidEye acquired at 5 $\mathrm{m}$ resolution on DOY 87 (March 28), 102 (April 12) and 151 (May 31) were atmospherically corrected to surface reflectances using 6S (Kotchenova et al., 2006) following the automated processing stream implemented in the regularized model inversion system, REGFLEC (Houborg et al., 2015b). To do this required spatially distributed information on aerosol optical depth at $550 \mathrm{~nm}$, total precipitable water and total ozone, which was acquired from the Terra MODIS aerosol product (MOD04), the Terra MODIS water vapor product (MOD05), and the Aura Ozone Monitoring Instrument (OMI), respectively. Needed information on vertical profiles of temperature, humidity and ozone were determined from the Aqua AIRS standard product and the aerosol type and profile was assumed from a background desert aerosol model (D’Almeida et al., 1991). Multi-spectral (blue, green, red, near-infrared) Landsat-8 data acquired at $30 \mathrm{~m}$ resolution on DOY 153 (June 2) were similarly corrected to surface reflectances.
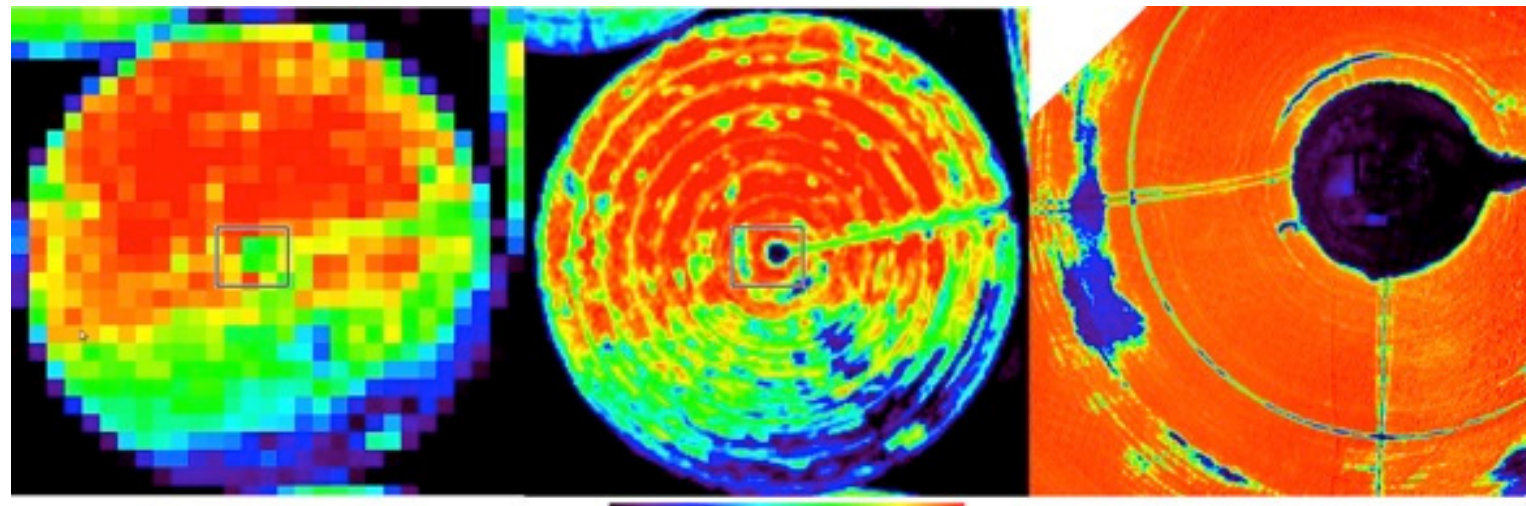

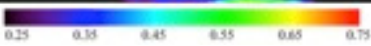

Figure 2. NDVI retrievals from (left-to-right) Landsat at $30 \mathrm{~m}$, RapidEye at $6 \mathrm{~m}$ and a single image from the Tetracam at approximately $10 \mathrm{~cm}$ resolution. Data were collected over an irrigated alfalfa field.

The raw uncalibrated Tetracam imagery collected on DOY 153 was translated into atmospherically corrected RapidEye consistent NDVI, by identifying bright and dark calibration targets to be used with the empirical line calibration method (Berni et al., 2009). Figure 2 demonstrates the derived multi-scale (30 $\mathrm{m}$ to around $\sim 10 \mathrm{~cm}$ ) features of NDVI over an irrigated alfalfa pivot field, located at the Tawdeehiya farm in the AlKharj region of Saudi Arabia. UAV data was collected from a flying height of approximately $500 \mathrm{ft}$. The high degree of within-field variability resulting from inefficient irrigation and soil variability can be seen, 
together with crop damage caused by the impacts of high winds in the few weeks before the UAV collection. The NDVI maps in Figure 2 feature data from near coincident satellite based retrievals including the freely available Landsat satellite, as well as the RapidEye commercial high-resolution system that provides 5 spectral bands at around $5 \mathrm{~m}$ resolution. Only a single image from the UAV is presented here as an example of the high-resolution detail available from these systems. As can be seen, the fine scale features of the crop circle are evident, including tire marks from the rotating pivot as well as within-field variability in crop condition. For instance, the low NDVI values (blue area in UAV retrieval) are the result of saturated soil conditions on-site, which limit crop growth. These features are evident in the RapidEye image (center of Fig 2), but largely absent at the Landscat scale, highlighting the multi-scale and heterogeneous nature of crop conditions.

To develop additional vegetation retrievals, LAI was retrieved from RapidEye data using a rule-based multivariate regression model established by Cubist (RuleQuest; www.rulequest.com). Cubist represents a data mining approach for identifying effective predictive models on the basis of a training dataset of observed target and explanatory variables. In this study, the training dataset consisted of in-situ LAI ( $\mathrm{n}=96)$ collected with a LICOR-2200C plant canopy analyzer in fields of alfalfa, grass, carrot and maize during field campaigns in March, April and June. The associated explanatory variables of appropriate spectral bands and vegetation indices (VIs) were extracted from RapidEye imagery within 2-5 days of the in-situ collections. A total of three rule-based models with varying contributions from the input spectral bands and VIs were constructed to map LAI during the RapidEye acquisitions, with an error of 0.17 and a Pearson's correlation coefficient of 0.97 . In order to avoid highly unrealistic LAI retrievals resulting from a non-representative predictive model assignment to a given pixel, the retrievals were compared against values of LAI calculated from NDVI using an exponential function established on a per-pivot basis. That is, if the Cubist and NDVI derived estimates diverged by more than 3 times the standard deviation of the exponential fit, the NDVI based estimate of LAI was used.

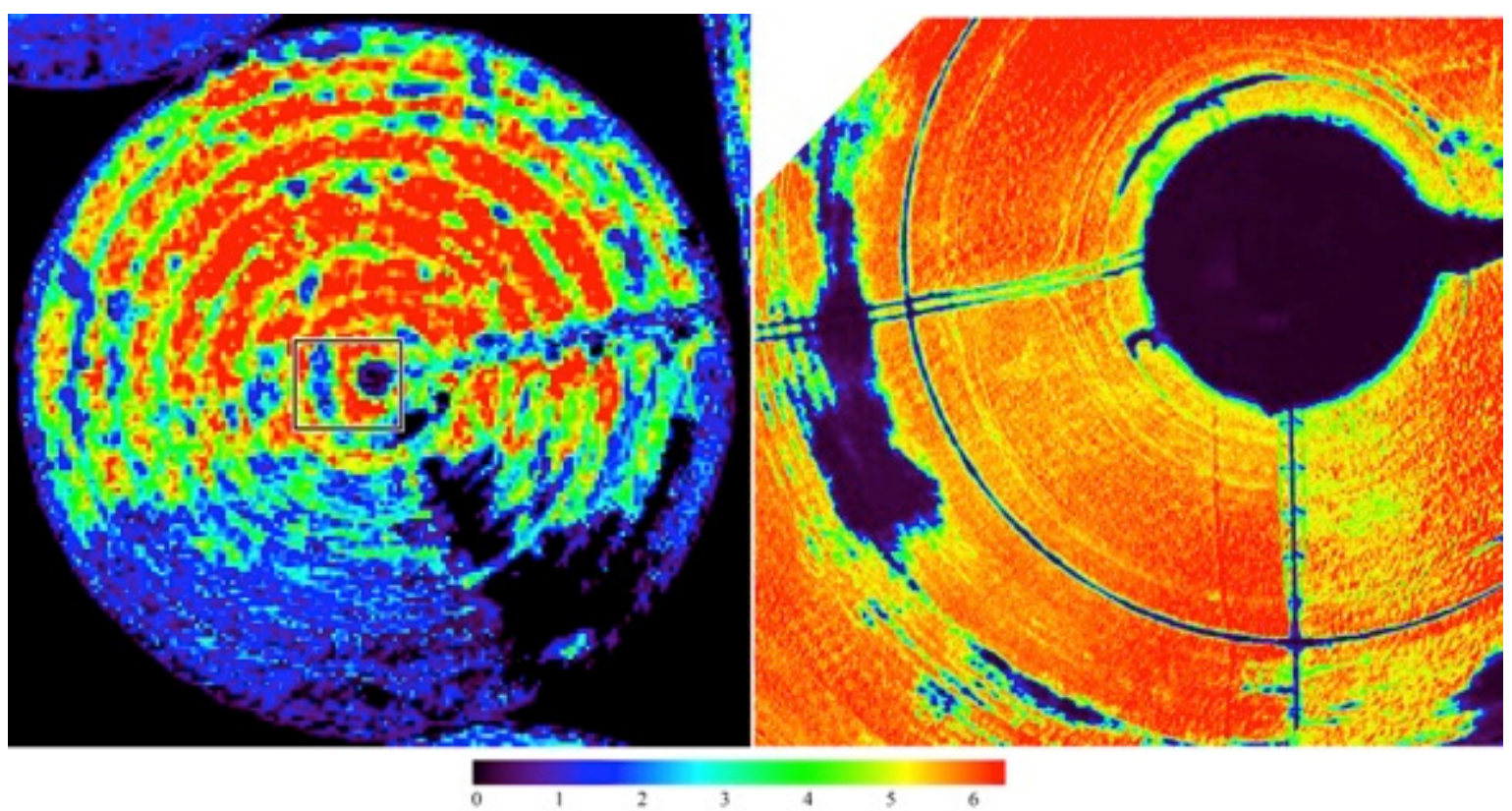

Figure 3. LAI derived from RapidEye data (left) using a multi-variate regression model based on in-situ measurements at the Tawdeehiya farm across a range of crop types. LAI for the UAV (right) was based on a simple exponential function linking NDVI with LAI at the RapidEye scale.

The UAV based LAI for the alfalfa field was derived from RapidEye LAI using a simple NDVI based downscaling approach. While Cubist identified two separate multi-variate regression models for mapping LAI over the alfalfa field, an exponential relationship between NDVI and LAI of the form:

$$
L A I=0.02297 e^{7.626 . N D V I}+0.2297
$$

provides a reasonable approximation for this specific pivot $(\mathrm{r}=0.96$, rmsd $=0.6$ or $16 \%)$. Given the consistency between Tetracam and RapidEye NDVI (Fig. 1) this relationship can be directly applied at the UAV scale with confidence (Fig. 2). 
Although only traditional metrics of plant health are shown here, bands in the red-edge region of the electromagnetic spectrum have proven informative in estimating leaf chlorophyll (Chl) content (Dash and Curran, 2004; Gitelson et al., 2008), which is of particular interest in precision agriculture applications (Haboudane et al., 2002). Likewise, indices based on the reflectance change in the green spectrum (Gitelson et al., 2002) are useful for estimating leaf carotenoids, which are involved in the xanthophyll pigment cycle that changes in response to photosynthetic down-regulation through non-photochemical quenching (Grace and Logan, 2000). Ongoing work will seek to develop maps of spatially distributed pigment concentrations (i.e. chlorophyll and carotenoids), which will serve as independent measures of plant health and condition, indirectly reflecting spatial variations in nitrogen availability and potential stress.

\section{DETERMINING LAND SURFACE TEMPERATURE FROM THE UAV DATA}

The availability of co-registered and spatially consistent visible-to-near-infrared (VNIR) (including red-edge bands) and thermal-infrared (TIR) data from our UAVs (see Fig. 1) is unique in a remote sensing context. This capacity provides an opportunity for investigating synergistic uses of these data for monitoring not only crop growth and vegetation vitality, but also water use. Since leaf temperatures respond directly to water stress through induced stomatal closure and decreased evaporative cooling, the integration of thermal infrared observations provides an additional means to detect vegetation stress before chlorophyll reductions take place (Gitelson et al., 2008; Houborg et al., 2011). Deriving such thermal and vegetation based products will aid not only in characterizing crop behavior throughout the growing season, but also offers an important observational constraint that can be integrated directly into coupled water and energy balance approaches for estimating evaporation or other hydrological processes (McCabe et al., 2005; Stisen and McCabe, 2012).

An Optris-Pi450 broadband thermal camera operating in the range 7.5-13 $\mu \mathrm{m}$ was flown in conjunction with the MiniMCA over the alfalfa field to map coincident vegetation and thermal response. As can be seen in Figure 4, there remain some artifacts as a result of sensor calibration sensitivity to high field temperatures during data collection (greater than $45^{\circ} \mathrm{C}$ ). Automated triggering and stamping of RTK based GPS time-stamps are in the process of being integrated into both UAV systems, which will improve the capacity for more accurate mosaicking. An inflight temperature regulation system is also being developed to reduce anomalous sensor response. Regardless, the image presents an excellent example of the high-resolution (approximately $20 \mathrm{~cm}$ ) thermal data that can be obtained from these UAV platforms. Further work will explore the synergies between the VNIR and thermal domains and exploit these for improving our understanding of crop water and energy balances, particularly as relates to precision agricultural applications.

\section{SUMMARY AND CONCLUSIONS}

Unmanned aerial vehicles offer an exciting approach to explore high-resolution detail on hydrological and agricultural processes in ways not available from conventional satellite or airborne systems. Furthermore, they are able to do this at an affordable entry point and are more compelling from both an economic and scientific perspective than expensive airborne campaigns or commercial satellite products. With an increasing range of thermal, multi- and hyper-spectral sensors available for UAV based operation, the research avenues that can be investigated with such systems is rapidly expanding. From an agricultural perspective, retrieving key characteristics on vegetation health and condition, as well as determining water use on a near real-time basis, offer the potential for significant development and growth in active crop management and precision agriculture applications. 
While the potential of UAVs for advancing knowledge of Earth system processes is considerable, community uptake has been hindered by a manufacturing focus on hardware developments, rather than on streamlining data processing chains to deliver useable products (Shahbazi et al., 2014; Zhang and Kovacs, 2012). Indeed, the applications science is in a state of playing catch-up to the rapid developments in technology. Furthermore, from a user perspective, there is still a considerable gap between being able to deploy these systems and then being able to make best use of the data they collect. For instance, while the flight technology is well advanced and the instrument capabilities are expanding, the integration of sensors retrievals with accurate space-time mapping of the surface is non-trivial. Issues of geolocational accuracy, image distortion, as well as radiometric and atmospheric correction complicate the production of variables of interest. Developing within field calibration approaches for the spectral and thermal data is key to ensuring retrieval accuracy, as are techniques for providing greater positional accuracy of mosaicked products. With rapidly expanding community uptake, such issues are being addressed via the development of improved postprocessing software and calibration approaches. Undoubtedly, UAVs are set to revolutionize the Earth observation community and open up new lines of research in the Earth and environmental sciences.

\section{ACKNOWLEDGEMENTS}

Research reported in this publication was supported by the King Abdullah University of Science and Technology (KAUST).

\section{REFERENCES}

Anderson, K. and Gaston, K.J., 2013. Lightweight unmanned aerial vehicles will revolutionize spatial ecology. Frontiers in Ecology and the Environment, 11(3): 138-146.

Berni, J.A.J., Zarco-Tejada, P.J., Suárez, L. and Fereres, E., 2009. Thermal and narrowband multispectral remote sensing for vegetation monitoring from an unmanned aerial vehicle. IEEE Transactions on Geoscience and Remote Sensing, 47(3): 722-738.

Carlson, T.N. and Ripley, D., 1997. On the relationship between NDVI, fractional vegetation cover and leaf area index. Remote Sens. Environ., 62(3): 241-252.

D’Almeida, G.A., Koepki, P. and Shettle, E.P., 1991. Atmospheric Aerosols, Global Climatology, and Radiative Characteristics. A. Deepak Publishing, Hampton, VA.

Dash, J. and Curran, P.J., 2004. The MERIS terrestrial chlorophyll index. Int. J. Remote Sens., 25(23): 54035413.

Dunbabin, M. and Marques, L., 2012. Robots for environmental monitoring: Significant advancements and applications. IEEE Robotics and Automation Magazine, 19(1): 24-39.

Ershadi, A., McCabe, M.F., Evans, J.P. and Walker, J.P., 2013. Effects of spatial aggregation on the multiscale estimation of evapotranspiration. Remote Sensing of Environment, 131: 51-62.

Ershadi, A., McCabe, M.F., Evans, J.P. and Wood, E.F., 2015. Impact of model structure and parameterization on Penman-Monteith type evaporation models. Journal of Hydrology, 525: 521535.

Ershadi, A., McCabe, M.F., Evans, J.P., Chaney, N.W. and Wood, E.F., 2014. Multi-site evaluation of terrestrial evaporation models using FLUXNET data. Agricultural and Forest Meteorology, 187: 4661.

Famiglietti, J.S., Lo, M., Ho, S.L., Bethune, J., Anderson, K.J., Syed, T.H., Swenson, S.C., de Linage, C.R. and Rodell, M., 2011. Satellites measure recent rates of groundwater depletion in California's Central Valley. Geophysical Research Letters, 38(3): n/a-n/a.

Gitelson, A.A., Zur, Y., Chivkunova, O.B. and Merzlyak, M.N., 2002. Assessing carotenoid content in plant leaves with reflectance spectroscopy. Photochemistry and Photobiology, 75(3): 272-281.

Gitelson, A.A., Viña, A., Masek, J.G., Verma, S.B. and Suyker, A.E., 2008. Synoptic monitoring of gross primary productivity of maize using landsat data. IEEE Geoscience and Remote Sensing Letters, 5(2): 133-137.

Grace, S.G. and Logan, B.A., 2000. Energy dissipation and radical scavenging by the plant phenylpropanoid pathway. Philosophical Transactions of the Royal Society B: Biological Sciences, 355(1402): 14991510 .

Haboudane, D., Miller, J.R., Tremblay, N., Zarco-Tejada, P.J. and Dextraze, L., 2002. Integrated narrowband vegetation indices for prediction of crop chlorophyll content for application to precision agriculture. Remote Sensing of Environment, 81(2-3): 416-426.

Hardin, P. and Jensen, R., 2011. Small-scale unmanned aerial vehicles in environmental remote sensing: Challenges and opportunities. GIScience and Remote Sensing, 48(1): 99-111. 
McCabe et al., The potential of unmanned aerial vehicles for providing information on vegetation health

Herwitz, S.R., Johnson, L.F., Dunagan, S.E., Higgins, R.G., Sullivan, D.V., Zheng, J., Lobitz, B.M., Leung, J.G., Gallmeyer, B.A., Aoyagi, M., Slye, R.E. and Brass, J.A., 2004. Imaging from an unmanned aerial vehicle: Agricultural surveillance and decision support. Comput. Electron. Agric., 44(1): 4961.

Houborg, R., McCabe, M.F., Cescatti, A. and Gitelson, A., 2015a. Leaf chlorophyll constraint on model simulated Gross Primary Productivity in agricultural systems. International Journal of Applied Earth Observation and Geoinformation, (in press).

Houborg, R., Anderson, M.C., Daughtry, C.S.T., Kustas, W.P. and Rodell, M., 2011. Using leaf chlorophyll to parameterize light-use-efficiency within a thermal-based carbon, water and energy exchange model. Remote Sensing of Environment, 115(7): 1694-1705.

Houborg, R., McCabe, M., Cescatti, A., Gao, F., Schull, M. and Gitelson, A., 2015b. Joint leaf chlorophyll content and leaf area index retrieval from Landsat data using a regularized model inversion system (REGFLEC). Remote Sensing of Environment, 159: 203-221.

Kalma, J., McVicar, T. and McCabe, M., 2008a. Estimating Land Surface Evaporation: A Review of Methods Using Remotely Sensed Surface Temperature Data. Surveys in Geophysics, 29(4): 421469.

Kotchenova, S.Y., Vermote, E.F., Matarrese, R. and Klemm, J.F.J., 2006. Validation of a vector version of the $6 \mathrm{~S}$ radiative transfer code for atmospheric correction of satellite data. Part I: Path radiance. Applied Optics, 45(26): 6762-6774.

Liu, Y.Y., de Jeu, R.A.M., McCabe, M.F., Evans, J.P. and van Dijk, A.I.J.M., 2011. Global long-term passive microwave satellite-based retrievals of vegetation optical depth. Geophys. Res. Lett., 38(18): L18402.

Mao, Y., Nijssen, B. and Lettenmaier, D.P., 2015. Is climate change implicated in the 2013-2014 California drought? A hydrologic perspective. Geophysical Research Letters: n/a-n/a.

McCabe, M.F. and Wood, E.F., 2006. Scale influences on the remote estimation of evapotranspiration using multiple satellite sensors. Remote Sensing of Environment, 105(4): 271-285.

McCabe, M.F., Kalma, J.D. and Franks, S.W., 2005. Spatial and temporal patterns of land surface fluxes from remotely sensed surface temperatures within an uncertainty modelling framework. Hydrol. Earth Syst. Sci., 9(5): 467-480.

McCabe, M.F., Balick, L.K., Theiler, J., Gillespie, A.R. and Mushkin, A., 2008. Linear mixing in thermal infrared temperature retrieval. Int. J. Remote Sens., 29(17-18): 5047-5061.

Nevill, C., 2009. Managing Cumulative Impacts: Groundwater Reform in the Murray-Darling Basin, Australia. Water Resour Manage, 23(13): 2605-2631.

Nex, F. and Remondino, F., 2014. UAV for 3D mapping applications: A review. Applied Geomatics, 6(1): 115 .

Shahbazi, M., Théau, J. and Ménard, P., 2014. Recent applications of unmanned aerial imagery in natural resource management. GIScience and Remote Sensing, 51(4): 339-365.

Stisen, S. and McCabe, M.F., 2012. Analysing parameter sensitivities in a complex distributed hydrological model using remotely sensed surface temperatures, IAHS-AISH Publication, pp. 292-295.

Tomic, T., Schmid, K., Lutz, P., Domel, A., Kassecker, M., Mair, E., Grixa, I., Ruess, F., Suppa, M. and Burschka, D., 2012. Toward a fully autonomous UAV: Research platform for indoor and outdoor urban search and rescue. IEEE Robotics and Automation Magazine, 19(3): 46-56.

Vivoni, E.R., Rango, A., Anderson, C.A., Pierini, N.A., Schreiner-Mcgraw, A.P., Saripalli, S. and Laliberte, A.S., 2014. Ecohydrology with unmanned aerial vehicles. Ecosphere, 5(10).

Watts, A.C., Ambrosia, V.G. and Hinkley, E.A., 2012. Unmanned aircraft systems in remote sensing and scientific research: Classification and considerations of use. Remote Sensing, 4(6): 1671-1692.

Zhang, C. and Kovacs, J., 2012. The application of small unmanned aerial systems for precision agriculture: a review. Precision Agric, 13(6): 693-712. 